Sampling strategy to select participants and their roles in a hearing - expert witness, inquiry panel, facilitator or audience; The type of evidence presented - scientific, professional or lay;

What counts as data and how deliberation is recorded;

Quality of deliberation and whether a consensus is achieved;

Ethical issues about the public nature of deliberation.

Conclusion Deliberative methods are under-utilised as a research method in public health; however, they require attention to design issues to secure genuine deliberation on a topic. This set of design choices will support researchers in generating and testing evidence through an expert hearing.

\section{P56 CHARACTERISTICS ASSOCIATED WITH CARDIOVASCULAR MULTIMORBIDITY IN UK WOMEN AGED 50-64 YEARS: CROSS-SECTIONAL ANALYSIS OF THE MILLION WOMEN STUDY}

JW Suh*, BJ Cairns, FL Wright. Nuffield Department of Population Health, University of Oxford, Oxford, UK

\subsection{6/jech-2019-SSMabstracts.207}

Background Multimorbidity, the co-occurrence of two or more chronic conditions in one person, is more common in women than in men. It is associated with lower life expectancy, lower quality of life, and greater use of health services compared to single diseases. Research on risk factors for cardiovascular multimorbidity (CVM), that is, having multiple cardiovascular diseases (CVDs), has been limited. We aimed to identify potential risk factors for CVM in women.

Methods The Million Women Study is a cohort of 1.3 million women aged 50-64 years, recruited in England and Scotland in 1996-2001 through NHS screening centres. Participants completed an extensive health and lifestyle questionnaire. Record linkage with NHS databases provided hospital admission records. Twenty chronic CVDs were selected based on clinical importance and number of records, primarily from chapter IX of the International Classification of Diseases v10. Characteristics were compared between women with 0,1 or $2+$ CVDs recorded in self-reports and hospital admissions up to recruitment, adjusting for five age categories (referent: 56-59 years).

Results Among 1,272,020 women, 0.7\% $(\mathrm{n}=8463)$ had CVM and $5.3 \%(66,805)$ had one CVD. The most common CVDs were ischaemic heart disease (4.7\%), stroke (1.2\%), atrial fibrillation (0.2\%), and venous thromboembolism (0.2\%); among those with CVM, 85\% had ischaemic heart disease and 54\% had stroke. Women with CVM were older and, after adjustment for age, were more likely to have common cardiovascular risk factors. In women with no CVDs and those with CVM, respectively: $19.2 \%(95 \%$ CI 19.2-19.3) and $25.1 \%$ (24.1-26.0) were current smokers; 39.4\% (39.4-39.6) and $22.7 \%(21.8-23.7)$ did strenuous physical activity at least once a week; mean BMI was $26.2(26.1-26.2)$ and 28.1 (28.0-28.2). Women with CVM were substantially more likely to be in the most deprived fifth and have no educational qualifications. There was little association between CVM and reproductive factors, although women who had ever breastfed were slightly less likely to have CVM. Women with no CVDs were much less likely to report treatment for diabetes, hypertension, and high cholesterol than those with CVM; $15.0 \%$ (14.9-15.1) and 43.9\% (42.9-45.0), respectively, were being treated for hypertension.
Conclusion Age-adjusted prevalence of CVM in UK women was associated with behavioural and socioeconomic characteristics, and with treatment for major cardiovascular risk factors, but largely not with reproductive factors. This cross-sectional study could not assess potential for reverse causation or confounding by other factors, and future prospective analyses will contribute to better understanding of these relationships.

\section{P57 TESTING THE IMPACT OF IAPT ON HEALTHCARE COSTS AND EMPLOYMENT: A STEP-WEDGE DESIGN}

${ }^{1} \mathrm{~V}$ Toffolutti ${ }^{*},{ }^{2}$ Thames Valley, ${ }^{3}$ Oxford Academic Network, ${ }^{4} \mathrm{M}$ McKee, ${ }^{1,5} \mathrm{D}$ Stuckler, ${ }^{3,6} \mathrm{D}$ Clark. ${ }^{1}$ Dondena Centre, Bocconi University, Milan, Italy; ${ }^{2}$ Thames Valley Clinical Commissioning Groups, Thames Valley Clinical Commissioning Groups, UK; ${ }^{3}$ Oxford Academic Network, University of Oxford, Oxford, The UK; ${ }^{4}$ Department of Public Health and Policy, London School of Hygiene and Tropical Medicine, London, UK; ${ }^{5}$ Department of Social and Political Science, Bocconi University, Milan, Italy; ${ }^{6}$ Department of Experimental Psychology, University of Oxford, Oxford, UK

\subsection{6/jech-2019-SSMabstracts.208}

Background According to the World Health Organization (WHO), depression is ranked as the single largest contributor to global disability. The Improving Access to Psychological Therapies (IAPT) programme is a large-scale initiative that aims to greatly increase the availability of NICE recommended psychological treatment for depression and anxiety disorders within the National Health Service in England. This study evaluates whether IAPT reduces healthcare utilization and associated health care costs and increases transition into employment.

Methods Gradual implantation of a stepped-wedge design of two cohorts covering 500 patients with depression and/or anxiety and comorbid long-term physical health conditions from three areas in Thames Valley (Berkshire, Oxfordshire and Buckinghamshire) for the period March 2017 - August 2017.

Results The wedge study findings showed a decrease in cost $£ 345$ total pp for 3 months so about $£ 115$ a month difference between the two cohorts. Results also showed a decrease by about 4.61[95\% CI: $-5.56,-3.66]$ (6.64 [95\% CI: -7.67, 5.61]) $[0.76$ [95\% CI: $-1.22,-0.30]]$ points per person in the GAD7 (PHQ9) [WASAS]. With respect to employment, results to find a job for those who were unemployment by about 29.9\% [95\% CI: 1.37-52.4], the marginal effects corresponds to 6.28 percentage points [95\% CI: 2.19-12.3].

Conclusion IAPT treatment was associated with a significant decline in secondary care costs and significant increase in the probability to find a job for unemployed patients.

Supported by an ERC Grant 313590-HRES. Also funded by Wellcome Trust.

\section{P58 ASSESSMENT OF CARDIOVASCULAR RISK IN A SLUM POPULATION IN KENYA: USE OF WORLD HEALTH ORGANIZATION/INTERNATIONAL SOCIETY OF HYPERTENSION (WHO/ISH) RISK PREDICTION CHARTS}

${ }^{1} \mathrm{~A}$ Vusirikala*, ${ }^{2} \mathrm{~F}$ Wekesah, ${ }^{2} \mathrm{C}$ Kyobutungi, ${ }^{1} \mathrm{O}$ Oyebode. 'Warwick Medical School, University of Warwick, Coventry, UK; ${ }^{2}$ African Population and Health Research Centre, (APHRC), Nairobi, Kenya

\subsection{6/jech-2019-SSMabstracts.209}

Background Although cardiovascular disease (CVD) is of growing importance in low- and middle-income countries (LMICs), 